\title{
An Overview of Obstructive Sleep Apnoea Syndrome and Oral Appliance Therapy
}

\author{
O Akinci Sozer ${ }^{1}$, F Bilgic $^{2}, \mathrm{H}_{\text {Altan }}^{3}$, C Aglarci ${ }^{4}$
}

\begin{abstract}
Oral appliances, one of the treatment options for obstructive sleep apnoea syndrome (OSAS), is used to treat mild and moderate OSAS. The aim of this study was to summarise the pathogenesis, epidemiology, diagnosis, and main treatment options of OSAS. A MedLine literature search was performed to identify articles associated with a dental approach to OSAS. It causes snoring, airway obstruction, and sleep disruption. Treating OSAS is important, and it can be managed successfully with an oral appliance. Oral appliances may be an alternative to other OSAS treatments because they are easily tolerated. Oral appliances offer a safe, effective, and noninvasive treatment option for OSAS.
\end{abstract}

Keywords: Oral appliance, review, sleep apnoea, sleep disorders

From: ${ }^{1}$ Department of Orthodontics, Faculty of Dentistry, University of Mustafa Kemal, Hatay, Turkey, ${ }^{2}$ Assistant Professor, Department of Orthodontics, Faculty of Dentistry, University of Mustafa Kemal, Hatay, Turkey, ${ }^{3}$ Department of Pediatric Dentistry, University of Mustafa Kemal, Hatay, Turkey, ${ }^{4}$ Department of Orthodontics, Faculty of Dentistry, University of Sifa, Izmir, Turkey.

Correspondence: Dr OA Sozer, Department of Orthodontics, Faculty of Dentistry, University of Mustafa Kemal, Hatay, Turkey. Fax: 00903262455060, e-mail:

ozlem.akinci@hotmail.com 


\section{INTRODUCTION}

Obstructive sleep apnoea syndrome (OSAS) is a respiratory sleep disorder that progresses into snoring, apnoea, and daytime sleepiness and can occasionally affect all organs and systems. OSAS is a condition characterised by frequent obstruction of the upper respiratory tract; thus, blood oxygen saturation decreases during sleep. Apnoea is usually terminated by noisy snoring or waking up. All individuals who snore are potential candidates for OSAS.

\section{Classification}

In 1997, the American Sleep Disorders Association (ASDA) defined OSAS as 'a disorder that is characterized by recurrent episodes of upper respiratory tract obstruction and decreased blood oxygen saturation during sleep'. OSAS classifications are based on apnoea-hypopnoea index (AHI) value (Table 1).

Table 1: OSAS Classification

\begin{tabular}{ll}
\hline AHI $<5$ & Normal \\
AHI $5-15$ & Mild \\
AHI $16-30$ & Moderate \\
AHI $>30$ & Severe \\
\hline
\end{tabular}

In 1991, ASDA (thereafter designated the American Academy of Sleep Medicine) developed the International Classification of Sleep Disorders. This classification included 84 sleep disorders corresponding to four main categories: dyssomnias, parasomnias, sleep disorders associated with other conditions, and proposed sleep disorders. 
In 2005, a novel classification system was published, the International Classification of Sleep Disorders-2, which includes 85 sleep disorders in eight categories:

1. Insomnias

2. Sleep-related breathing disorders

3. Hypersomnias of central origin

4. Circadian rhythm sleep disorders

5. Parasomnias

6. Sleep-related movement disorders

7. Isolated symptoms, apparently normal variants

8. Other sleep disorders

Sleep apnoea is classified as a sleep-related breathing disorder. Snoring alone, even without apnoea, is an important issue, as it impairs sleep quality and causes inconvenience to others. It should be addressed carefully, as it indicates the possibility of sleep apnoea, but not all individuals with apnoea have OSAS.

It is critical to identify whether OSAS is present in patients with a complaint of snoring. Primary snoring is a social disorder with optional treatments. However, OSAS is a disorder that can cause serious morbidity and even mortality, and treatment is warranted. Polysomnography (PSG) is the only definitive test for identifying OSAS.(1-3)

\section{Epidemiology}

The prevalence rate of OSAS is estimated to be $1.2-2.5 \%$ in the adult female population and $1-5 \%$ in the adult male population. $(4,5)$ In 1995 , Stradling(6) conducted a study to assess 
prevalence based on AHI criteria by reviewing prevalence studies conducted since the 1980 s (Table 2).

Table 2: OSAS prevalence based on AHI criteria

\begin{tabular}{ll}
\hline Criteria & Prevalence $\%$ \\
\hline AHI $>5$ & $1.5-5$ \\
AHI $>10$ & $0.8-3$ \\
AHI $>20$ & $0.3-0.7$ \\
\hline
\end{tabular}

\section{Diagnostic Methods}

The various methods used for diagnosing OSAS can be classified as follows:

1. Clinical diagnosis

2. Radiological diagnosis

3. Endoscopic diagnosis

4. Polysomnography

5. Ancillary methods

PSG, the gold standard in the diagnosis of OSAS, can make a definitive diagnosis. However, other diagnostic modalities are necessary to achieve a definitive diagnosis, as PSG requires a specialised team, it is expensive and time consuming, and there is an inadequate number of qualified sleep laboratories both in our country and worldwide. Patients who undergo PSG can be selected using the following methods. $(1,7-9)$

\section{Clinical Diagnosis}

Conceivably, clinical diagnosis is the most important method among diagnostic modalities other than PSG (Table 3).

Table 3: Clinical symptoms of OSAS 
I. Major Symptoms

1. Snoring

2. Witnessed apnoea

3. Excessive daytime sleepiness

II. Cardiopulmonary Symptoms

1. Nocturnal arrhythmias

2. Gasping or choking sensation during sleep

3. Atypical chest pain

III. Neuropsychiatric Symptoms

1. Morning headaches

2. Inadequate and interrupted sleep

3. Decreased decision-making ability

4. Impaired memory; forgetfulness

5. Decreased attention

6. Personality disorder

7. Adjustment disorder

8. Depression, anxiety, psychosis

9. Abnormal motor activity during sleep

IV. Other Symptoms

1. Night sweats

2. Nocturnal cough

3. Hearing loss

4. Dry mouth

5. Gastroesophageal reflux disease

Although there is no single physical examination to establish a definitive diagnosis, physical examination has a role in identifying related risk factors and diseases. The assessment of cases using a multidisciplinary approach that includes chest disease specialists, otolaryngologists, 
cardiologists, neurologists, psychiatrists, and dentists provides a significant contribution to both the diagnosis and management of OSAS.

Some findings related to OSAS can be observed in the upper respiratory tract. These characteristics include increased oropharyngeal tissue, long and loose soft palate, low palatal arc, large tongue, hypertrophic tonsils, thickened lateral pharyngeal bands, and nasal septum deviation. A small mandible increases the likelihood of OSAS.

\section{Radiological diagnosis}

\section{Static radiological diagnostic modalities}

Cephalometry: Dentists contribute to the multidisciplinary management of OSAS by interpreting findings obtained from cephalometric radiographs. Cephalometric radiographs can reveal morphological problems related to the maxilla or mandible, craniofacial abnormalities, soft tissue abnormalities of the upper respiratory tract, a large soft palate, micrognathia, retrognathia, a large tongue, an inferiorly localised hyoid bone, and a stenotic posterior airway, all of which can play role in the etiology of OSAS.(10)

Computed tomography (CT): $\mathrm{CT}$ is a three-dimensional imaging modality that provides detailed data regarding the dimensions, adjacent tissues, and diameter of the upper respiratory tract due to its superior resolution for bone and soft tissue.(11, 12)

Magnetic resonance imaging (MRI): MRI is a three-dimensional imaging modality that provides superior results for soft tissues of the upper respiratory tract. It provides good results in the imaging of fat tissue accumulation at the soft palate and the periepiglottic space. MRI is not used as routinely.(13)

\section{Dynamic radiological diagnostic modalities}

Somnofluoroscopy: In this method, the pharyngeal region is coated with barium and the head is elevated $30^{\circ}$ for better imaging of the hypopharynx. Although it is superior to other 
modalities in imaging the upper respiratory tract and changes in soft tissues during sleep, it does not allow measurement of the upper respiratory tract and its cross-sectional area.(14)

Acoustic reflection: Using sonic waves, this method provides an estimate of the crosssectional area of the upper respiratory tract.(15)

\section{Endoscopic Diagnosis}

Endoscopic diagnosis involves the identification of an obstruction site by using a nasal endoscopy technique, in order to select the optimal therapeutic approach.(16)

Polysomnography

PSG is the general term used to describe recording techniques and methods used to detect sleep disorders in sleep laboratories.(17) This procedure includes the simultaneous and continuous recording of neurophysiological, respiratory, cardiovascular, physical, and physiological parameters throughout night, in a periodic manner. The parameters required to be recorded in PSG include electroencephalography, electrooculography, electromyography, oronasal air flow, thoracoabdominal movements, oxygen saturation, electrocardiography, and body position. The severity of OSAS is rated according to AHI detected in PSG; the grading is critical in the selection of a therapeutic approach. However, the selection of patients for PSG is important due to the requirement for a specialised team for polysomnography, the expensive and time-consuming nature of this method, and the inadequate number of qualified sleep laboratories.

\section{Treatment of OSAS}

Early diagnosis and, more importantly, appropriate management are critically important for patients with OSAS, a disorder that has serious consequences, including death during sleep. As such, AHI values are important in patients with OSAS. Although treatment is planned according to AHI value, it is necessary to plan treatment by assessing each patient individually, considering the pros and cons of treatment and obtaining the patient's consent. 
The treatment modalities include positive airway pressure therapy, surgical treatment, and intraoral appliances.

\section{Positive Airway Pressure Therapy}

\section{Continuous positive airway pressure (CPAP)}

A CPAP device is a device that provides patency of the upper respiratory tract mechanically by providing room air to the patient at a certain pressure level. The system includes a highspeed generator, a low-resistance tube, a pressure regulator, and a nasal mask. The device provides constant upper respiratory tract pressure by decreasing flow at the same level of pressure that increases during expiration and increasing flow at the same amount of pressure that decreases during inspiration.(18)

PSG studies of OSAS patients using CPAP therapy have shown that apnoea-hypopnea episodes disappear, increased respiratory efforts and heart rate return to normal, and oxygen saturation levels increase. CPAP therapy can improve all OSAS complications when it is successful.

CPAP-related side effects are rare. The most frequent adverse events include intolerance to breathing pressurised air, nasal congestion, and cutaneous irritations caused by the mask Bilevel positive airway pressure (BPAP)

BPAP was developed as an alternative to CPAP. During sleep, airway resistance and the tendency toward airway obstruction are higher during expiration compared to inspiration. Thus, the aim of BPAP is to achieve better tolerance by applying lower pressure during expiration than during inspiration, rather than applying constant pressure. $(19,20)$

\section{Auto-titrating positive airway pressure (APAP)}

Resistance of the upper respiratory tract changes according to variables such as body position, stage of sleep, body weight, and nasal congestion. Thus, optimal PAP required by an individual varies daily and even hourly. The APAP system has no constant pressure. Pressure 
is occasionally elevated to prevent apnoea, and it changes throughout the night. Because pressure is raised by this device based on the patient's status, it can be tolerated more easily. However, this method is rather expensive and the outcomes of long-term use are unknown.(21)

\section{Surgical treatment}

Surgical treatment can be used when a definitive obstruction site is identified in patients with OSAS. The surgical method should include corrective techniques, and serious surgical procedures should be reserved for patients' refractory to all other therapeutic attempts. Age, severity of OSAS, presence of systemic problems, severity of snoring, physical examination findings of the upper respiratory tract, occupation, declination or intolerance of PAP therapy, and surgical and technical capacity of the facility all have a role in the selection of patients who are good candidates for this surgery.(22)

\section{Intraoral device therapy}

Intraoral devices, which are inserted in the mouth before sleeping, are used to widen the airway by changing the position of upper respiratory tract components; to decrease resistance by influencing muscle function; and to prevent collapse of the upper airway.(23) Dental and skeletal complications are rarely seen with this therapy. Although it seems that it would be difficult to tolerate, compliance is generally good. This method is an alternative treatment modality used in patients with mild or moderate OSAS who cannot tolerate CPAP therapy.(24, 25) The important factors to consider during the dental examination include assessments of the soft tissues, oral cavity, periodontium, occlusion, and temporomandibular joint; radiographs obtained within the previous six months; diagnostic casts; and the patient's habits.(25) 
Intraoral device application in the treatment of OSAS was first used by Boraz et al. in 1979.(26) Today, there are more than 80 commercially available intraoral devices, (27) which are classified into three main categories based on therapeutic principles: mandibular advancement devices (MAD), tongue retaining devices (TRD), and palate lifting appliances.

\section{Mandibular advancement devices}

The aim of MAD devices is to widen and stabilise the distance between the root of the tongue and the oropharynx by advancing the mandible forward. $(28,29)$ These devices have varying effects on the airway. They change the geometry of the pharyngeal region, resulting in a larger retropalatal area due to the increased size in the lateral aspect. The amount of increase in the lateral diameter of the airway is greater than the increase in sagittal diameter, and the increase in size of both the lateral and sagittal directions at the retroglossal level result in an increased pharyngeal area.(12) MAD is appropriate for use in mild or moderate OSAS cases with micrognathia, obese patients, and patients incapable of nasal breathing.

The patient-related factors that have a role in the successful use of these devices include normal or decreased facial length, normal position of mandible according to cranial base, normal intermaxillary distance, small ratio of soft palate or tongue to functional area, and at least eight teeth in the mandible and maxilla. A thicker soft palate and excessive tongue area can cause failure of mandibular advancement devices.

\section{Tongue-retaining devices}

TRDs were first used by Cartwright and Samelson in 1982.(30) In this method, the tongue is retracted anterior to the incisors and stabilised during sleep. Activity of the genioglossus muscle is increased in OSAS patients using this device,(31) leading to increased volume and decreased resistance of the upper airway. These devices are preferred in patients with large tongues, patients with chronic temporomandibular joint pain that prevents anterior shifting of the mandible, and patients with fewer than six teeth in each arc. It has been reported that 
while AHI value typically decreases by $50 \%$ in $50-75 \%$ of patients, AHI decreased below $10 \%$ in $25-73 \%$ of patients using TRD therapy. $(29,32,33)$

Palate-stabilising devices

Palate-stabilising devices reduce the vibration that causes snoring by stabilising the soft palate.(34) These devices are rarely used because it is difficult to tolerate them.

\section{Indications for Intraoral Device Use}

- $\quad$ Patients with simple snoring $(\mathrm{AHI}<5)$

- Patients with mild OSAS who respond poorly to general measures such as weight loss or appropriate sleep position

- Patients with mild to moderate OSAS who are intolerant of or decline CPAP therapy

- Patients who are candidates for tonsillectomy, adenoidectomy, craniofacial surgery, or tracheotomy, but who do not agree to undergo such surgeries

- Patients with upper airway resistance (particularly for snoring)

- Patients who have undergone uvulopalatopharyngoplasty but are still experiencing problems

\section{Contraindications for Intraoral Device Use}

- Patients with poor general status

- Patients without an adequate number of teeth or healthy teeth

- Patients with severe hypoxemia during sleep

- Patients with a temporomandibular joint abnormality or problem

- Patients with nasal obstruction

- Patients with periodontal disease or inadequate oral hygiene 
- Patients with central sleep apnoea

- Patients with history of previously failed intraoral device

\section{CONCLUSION}

An increasing number of studies have shown that oral devices that position the mandible forward are highly successful alternatives in controlling OSAS. When the risks and benefits of oral appliance therapy are compared with other treatment modalities, it becomes an increasingly popular alternative. A well-planned, evidence-based oral appliance therapy administered by a dentist exhibits therapeutic effectiveness comparable to those of other invasive and non-invasive methods in the treatment of OSAS. Oral appliance therapy can be demonstrated by PSG, and it provides improvement in daytime sleepiness and the resulting social complications in patients with OSAS. 


\section{REFERENCES}

1. Battagel JM, Johal A, L'Estrange PR, Croft CB, Kotecha B. Changes in airway and hyoid position in response to mandibular protrusion in subjects with obstructive sleep apnoea (OSA). Eur J Orthod 1999; 21: 363-76.

2. Johal A, Battagel JM. An investigation into the changes in airway dimension and the efficacy of mandibular advancement appliances in subjects with obstructive sleep apnoea. Br J Orthod 1999; 26: 205-10.

3. Cooke ME, Battagel JM. A thermoplastic mandibular advancement device for the management of non-apnoeic snoring: a randomized controlled trial. Eur J Orthod 2006; 28: 327-38.

4. Gislason T, Benediktsdottir B, Bjornsson JK, Kjartansson G, Kjeld M, Kristbjarnarson H. Snoring, hypertension, and the sleep apnea syndrome. An epidemiologic survey of middle-aged women. Chest 1993; 103: 1147-51.

5. Young T, Palta M, Dempsey J, Skatrud J, Weber S, Badr S. The occurrence of sleepdisordered breathing among middle-aged adults. N Engl J Med 1993; 328: 1230-5.

6. Stradling JR. Sleep-related breathing disorders. 1. Obstructive sleep apnoea: definitions, epidemiology, and natural history. Thorax. 1995; 50: 683-9.

7. Battagel JM, L'Estrange PR, Nolan P, Harkness B. The role of lateral cephalometric radiography and fluoroscopy in assessing mandibular advancement in sleep-related disorders. Eur J Orthod. 1998; 20: 121-32.

8. Gale DJ, Sawyer RH, Woodcock A, Stone P, Thompson R, O'Brien K. Do oral appliances enlarge the airway in patients with obstructive sleep apnoea? A prospective computerized tomographic study. Eur J Orthod 2000; 22: 159-68. 
9. Johal A, Battagel JM, Kotecha BT. Sleep nasendoscopy: a diagnostic tool for predicting treatment success with mandibular advancement splints in obstructive sleep apnoea. Eur J Orthod 2005; 27: 607-14.

10. Cobo J, de Carlos F, Diaz Esnal B, Fernandez MP, Llorente S, Llorente J. [Changes in the upper airway in patients with sleep obstructive apnea and/or chronic snoring treated with mandibular appliances]. Acta otorrinolaringologica espanola 2001; 52: $470-4$.

11. Tso HH, Lee JS, Huang JC, Maki K, Hatcher D, Miller AJ. Evaluation of the human airway using cone-beam computerized tomography. Oral surgery, oral medicine, oral pathology, oral radiology, and endodontics 2009; 108: 768-76.

12. Kyung SH, Park YC, Pae EK. Obstructive sleep apnea patients with the oral appliance experience pharyngeal size and shape changes in three dimensions. The Angle orthodontist. 2005; 75: 15-22.

13. Ciscar MA, Juan G, Martinez V, Ramon M, Lloret T, Minguez J, et al. Magnetic resonance imaging of the pharynx in OSA patients and healthy subjects. Eur Respir J 2001; 17: 79-86.

14. Levy P, Pepin JL, Ferretti G. [The dynamics of pharyngeal structures in obstructive sleep apnea (during spontaneous, continuous positive pressure and BiPAP ventilation)]. Neurophysiologie clinique $=$ Clin Neurophysiol 1994; 24: 227-48.

15. Agarwal SS, Jayan B, Kumar S. Therapeutic efficacy of a hybrid mandibular advancement device in the management of obstructive sleep apnea assessed with acoustic reflection technique. Indian J Dent Res 2015; 26: 86-9.

16. Faber CE, Grymer L. Available techniques for objective assessment of upper airway narrowing in snoring and sleep apnea. Sleep \& breathing = Schlaf \& Atmung. 2003; 7: $77-86$. 
17. Man GC. Obstructive sleep apnea. Diagnosis and treatment. Med Clin North Am. 1996; 80: 803-20.

18. Weaver TE, Chasens ER. Continuous positive airway pressure treatment for sleep apnea in older adults. Sleep medicine reviews 2007; 11: 99-111.

19. Mansukhani MP, Kolla BP, Olson EJ, Ramar K, Morgenthaler TI. Bilevel positive airway pressure for obstructive sleep apnea. Expert Rev Med devices. 2014; 11: 28394.

20. Sanders MH, Montserrat JM, Farre R, Givelber RJ. Positive pressure therapy: a perspective on evidence-based outcomes and methods of application. Proceedings of the American Thoracic Society 2008; 5: 161-72.

21. Berry RB, Parish JM, Hartse KM. The use of auto-titrating continuous positive airway pressure for treatment of adult obstructive sleep apnea. An American Academy of Sleep Medicine review. Sleep 2002; 25: 148-73.

22. Smith DF, Cohen AP, Ishman SL. Surgical management of OSA in adults. Chest 2015; 147: 1681-90.

23. Sutherland K, Vanderveken OM, Tsuda H, Marklund M, Gagnadoux F, Kushida CA, et al. Oral appliance treatment for obstructive sleep apnea: an update. J Clin Sleep Medicine: 2014; 10: 215-27.

24. Wiegand L, Zwillich CW. Obstructive sleep apnea. Disease-a-month : DM 1994; 40: $197-252$.

25. Schmidt-Nowara W, Lowe A, Wiegand L, Cartwright R, Perez-Guerra F, Menn S. Oral appliances for the treatment of snoring and obstructive sleep apnea: a review. Sleep 1995; 18: 501-10.

26. Boraz RA, Martin HE, Michel JD. Sleep apnea syndrome: report of case. ASDC J Dentistry Children 1979; 46: 410-2. 
27. Lowe AA. Orthodontists and sleep-disordered breathing. Am J Orthod Dentofacial Orthoped 2006; 129: 194.

28. Ryan CF, Love LL, Peat D, Fleetham JA, Lowe AA. Mandibular advancement oral appliance therapy for obstructive sleep apnoea: effect on awake calibre of the velopharynx. Thorax 1999; 54: 972-7.

29. Kato J, Isono S, Tanaka A, Watanabe T, Araki D, Tanzawa H, et al. Dose-dependent effects of mandibular advancement on pharyngeal mechanics and nocturnal oxygenation in patients with sleep-disordered breathing. Chest 2000; 117: 1065-72.

30. Cartwright RD, Samelson CF. The effects of a nonsurgical treatment for obstructive sleep apnea: the tongue-retaining device. Jama 1982; 248: 705-9.

31. Ono T, Lowe AA, Ferguson KA, Pae EK, Fleetham JA. The effect of the tongue retaining device on awake genioglossus muscle activity in patients with obstructive sleep apnea. American journal of orthodontics and dentofacial orthopedics : official publication of the American Association of Orthodontists, its constituent societies, and the American Board of Orthodontics. 1996; 110: 28-35.

32. Montserrat J, Ballester E, Hernandez L. Overview of management options for snoring and sleep apnoea. Eur Respir Mon 1998; 10:144-78.

33. Pancer J, Al-Faifi S, Al-Faifi M, Hoffstein V. Evaluation of variable mandibular advancement appliance for treatment of snoring and sleep apnea. Chest 1999; 116: 1511-8.

34. Bailey DR. Tension headache and bruxism in the sleep disordered patient. Cranio: 1990; 8: 174-82. 